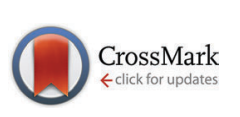

Cite this: Phys. Chem. Chem. Phys., 2016, 18, 24134

DOI: $10.1039 / c 6 c p 90206 e$

\section{Correction: Enhanced photocatalytic activity of a self-stabilized synthetic flavin anchored on a $\mathrm{TiO}_{2}$ surface}

\author{
Manjula Pandiri, ${ }^{a}$ Nurit Shaham-Waldmann, ${ }^{a}$ Mohammad S. Hossain, ${ }^{b}$ \\ Frank W. Foss Jr., ${ }^{b}$ Krishnan Rajeshwar ${ }^{b}$ and Yaron Paz*a
}

Correction for 'Enhanced photocatalytic activity of a self-stabilized synthetic flavin anchored on a $\mathrm{TiO}_{2}$ surface' by Manjula Pandiri et al., Phys. Chem. Chem. Phys., 2016, 18, 18575-18583.

The authors would like to correct a mistake in the original paper by adding Dr Nurit Shaham-Waldmann as a co-author. Dr Nurit Shaham-Waldmann developed the reactor that was used, performed part of the activity tests, and was responsible for the NMR characterization results with the loaded photocatalyst.

The Royal Society of Chemistry apologises for these errors and any consequent inconvenience to authors and readers.

\footnotetext{
${ }^{a}$ Department of Chemical Engineering, Technion, Haifa 32000, Israel.E-mail: paz@tx.technion.ac.il

${ }^{b}$ Department of Chemistry and Biochemistry, The University of Texas at Arlington, Arlington, 76019-0065, TX, USA
} 